\title{
Assessing behavioral patterns of Internet addiction and drug abuse among high school students
}

This article was published in the following Dove Press journal:

Psychology Research and Behavior Management

25 January 2017

Number of times this article has been viewed

\section{Zeinab Nemati \\ Hossein Matlabi}

Department of Health Education and Promotion, Faculty of Health Sciences, Tabriz University of Medical Sciences, Tabriz, Iran
Correspondence: Hossein Matlabi Department of Health Education and Promotion, Faculty of Health Sciences, Tabriz University of Medical Sciences, Attar Neishabouri Street, Tabriz 51656658 II, Iran

Tel +989141008927

Fax +984133344731

Email hm1349@gmail.com
Background: Internet addiction and drug abuse isolate adolescents from their family and friends and cause damage to their health, relations, emotions, and spirit. In the society, adolescents' addiction extracts high cost on health care, educational failure and mental health services.

Objectives: The aim of this study was to assess the behavioral patterns of Internet and drug addiction among urban and rural students in Urmia, Iran.

Methods: A sectional and descriptive-analytical approach with stratified sampling method was employed to recruit 385 high school students from urban and rural areas. The Internet Addiction Test (IAT) and the Addiction Acknowledgement Scale (AAS) were used for data collection.

Results: The total score of Internet addiction among the students was $41.72 \pm 17.41$. Approximately two-third of the students were not addicted to the Internet. The mean score of the AAS was $1.87 \pm 1.23$ among boys and $1.75 \pm 1.31$ among girls. Moreover, $8.31 \%$ of the students were prone to abusing substances. A statistically significant relationship was found between mother's literacy level and Internet addiction behavior of students $(p=0.009)$.

Conclusion: Concentrating on adolescents' behavioral patterns and their tendency toward misusing Internet and drugs is a notable procedure. Therefore, focusing on adolescents' health and institutionalizing appropriate training programs for adolescents and their families are vital.

Keywords: Internet, drug abuse, adolescence, addiction, behavior

\section{Introduction}

There are $\sim 1.2$ billion adolescents in the age group of 10-19 years in the world. Adolescence is a critical period for the formation of lifestyle-related patterns, and adolescents experience physical, mental, and social interactional changes during this period. ${ }^{1-3}$ As mortality and morbidity risk factors in this age group have shifted from infectious to behavioral factors over the past years ${ }^{4-6}$ and, on the other hand, many health risk behaviors in adolescence are associated with disabilities and diseases throughout their lives, focusing on the behavioral risk factors must be considered for more research. ${ }^{7,8}$

Expansion of personal computers and increase in Internet connection at home and workplace have led to the advent of a dilemma called online addiction among adolescents. Internet addiction is described as uncontrollable and damaging use of the Internet and is recognized as a compulsive Internet usage disorder. ${ }^{9}$ Internet users have increased by 15\% between 1992 and 2000 in the whole world. Like other types of addiction, this kind of addiction isolates adolescents from their family and friends and causes damage to their health, relations, emotions, and spirit. Based on the latest research in Iran, most of the Internet users are youth, $35 \%$ of whom are in chat rooms, $28 \%$ play Internet games, and 25\% search the World Wide Web. ${ }^{10-12}$ The abuse of 
alcohol and drugs during adolescence and early adulthood is another serious public health problem. ${ }^{13}$ The consequences of drug abuse are acute on both individual and social circumstances. Drug abuse demoralizes motivation, interferes with cognitive processes, and contributes to debilitating mood disorders and accidental injuries. In the society, adolescents' addictions extract high cost on health care, educational failure, and mental health services. ${ }^{14}$ Studies have indicated that $22.4 \%$ of Iranian adolescents smoke and also $9.6 \%$ and $10.8 \%$ use alcohol and drugs. ${ }^{15}$ West Azerbaijan Province is in the northwest of the country, bordering Turkey, Iraq and Azerbaijan's Nakhchivan Autonomous Republic. Urmia, the capital, is linked to Europe through Turkey's roads and the principal exit point for drugs transiting, making accessibility to drugs easy. Moreover, unemployment and social distractions are evident in Urmia. Thus, despite the previous studies accomplished in other states of Iran, we aimed to assess the behavioral patterns of both Internet addiction and drug abuse among adolescents in Urmia.

As $>90 \%$ of children and adolescents spend a considerable amount of time of the day at school, which is a great place for developing regular contact with adolescents, schools can provide an appropriate environment for training a healthy lifestyle for adolescents. ${ }^{16}$ Given the serious consequences of Internet addiction and drug abuse among adolescents and their devastative impact on physical and mental health, this study was aimed to evaluate the prevalence of risky behaviors such as Internet addiction and its related factors among students and adolescents of urban-rural schools. We hope the results of this study would be useful for developing health-oriented programs in the future.

\section{Methods}

\section{School setting and participants}

This study was designed and implemented using a sectional and descriptive-analytical approach. According to the following equation, the sample size was calculated based on the $95 \%$ confidence interval and 50\% health behavior performance.

$$
n=\frac{z^{2}\left[1-\frac{a}{2}\right] \times p q}{d^{2}}=\frac{1.96^{2} \times .5 \times .5}{0.05^{2}}=385
$$

Regarding the dispersion of students in urban and rural schools, stratified sampling method was used to recruit 26 schools (12 private schools and 14 public schools) from 6 education zones of the city. Eventually, 194 boys and 191 girls who had access to the Internet via cell phone or computers were invited to participate in the study, and participants were ineligible if they had severe impairment or were too frail to undertake the survey.

\section{Ethical considerations}

This study was approved by the ethical review committee of the Tabriz University of Medical Sciences (Institutional Review Board approval no: 5/4/4878-20/08/2014). The required coordination was also done with the Ministry of Education and directors of educational zones and schools. Confidentiality of the information and making students aware of optional participation in the study were also considered. The purpose of the study was explained to all students, and written informed consent was obtained.

\section{Output measures}

Data of the study were collected through sociodemographic items, including gender, student's field of study, types of school (private or public), parents' literacy, and students' residence; Internet Addiction Test (IAT); and the Addiction Acknowledgement Scale (AAS).

The Internet addiction questionnaire includes 20 Likertscale responses. The range of the scores is from 20 to 100 , where higher scores indicate a greater level of addiction. A score of 20-49 points is categorized as average online user, 50-79 points as occasional or frequent problems because of the Internet, and 80-100 points as Internet usage is causing significant problems. ${ }^{17}$

The AAS is a subscale of the Minnesota Multiphasic Personality Inventory-2 (MMPI-2) scale that detects alcohol/drug abuse problems in the context of a general personality assessment. The scale includes 13 questions with false or true responses. The correct response to each question earns a point. ${ }^{18,19}$ Owing to certain restrictions from the education organizations, a few of the questions related to sexual behaviors, alcohol, and specific drugs were eliminated. Both scales were previously translated to Persian, and standardized versions have been used in Iran. ${ }^{20,21}$

\section{Procedure}

The questionnaires and other documents for getting permission were sent to the head office of the ministry of education, and their verifications were obtained. Then, letters related to students' cooperation with researchers were sent to all the education zones. In addition, general information related to students' population as well as phone number and address of schools were acquired. Finally, after making the required coordination in each educational zone and with the principals and obtaining written consent from students, the questionnaires were completed by self-reporting and interviewing each student individually. 


\section{Data analysis}

The obtained data were analyzed using descriptive statistics, independent $t$-test, and analysis of variance. Additionally, multivariate logistic regression analysis was applied to find a relationship between sociodemographic variables and being prone to abusing substances. All statistical tests were two sided with a $p$-value $<0.05$ considered statistically significant.

\section{Results}

A total number of 385 students, including 194 boys and 191 girls, participated in this study. Of all these students, $76.9 \%$ were from public schools and $23.1 \%$ were from private schools. Also, $83.4 \%$ were living in the city and $16.6 \%$ were from rural areas. Additionally, $19.2 \%$ were studying in the field of mathematics, $19.5 \%$ experimental sciences, $18.7 \%$ humanities, $22.3 \%$ vocational, and $20.3 \%$ technical. The sociodemographic characteristics are summarized in Table 1.

The total score of Internet addiction among the students was $41.72 \pm 17.41$, and the range of scores was from 20 to 100. Approximately two-third of the students had lack of Internet addiction, $25.2 \%$ had average dependency, and 3.6\% had severe dependency.

Using multivariable regression analysis, a statistically significant relationship was found between mother's literacy level and Internet addiction behavior of students $(p=0.009)$. Based on the results of independent $t$-test, there were no significant relationships between school types, gender, fields

Table I Frequency of sociodemographic characteristics of participants $(\mathrm{N}=385)$

\begin{tabular}{ll}
\hline Variable & $\mathbf{n}(\%)$ \\
\hline Gender & \\
Male & $194(50.4)$ \\
Female & $191(49.6)$ \\
Type of school & \\
Free public school & $296(76.9)$ \\
Private school & $89(23.1)$ \\
Fields of education & \\
Math and physics & $74(19.2)$ \\
Experimental sciences & $75(19.5)$ \\
Humanities and literature & $72(18.7)$ \\
Applied sciences & $164(42.6)$ \\
Family residence & \\
Rural & $64(16.6)$ \\
Urban & $321(83.4)$ \\
Mother's level of education & \\
Primary school & $114(29.6)$ \\
High school & $197(51.1)$ \\
Undergraduate & $74(19.3)$ \\
Father's level of education & \\
Primary school & $63(16.4)$ \\
High school & $206(53.5)$ \\
Undergraduate & $116(30.1)$ \\
\hline
\end{tabular}

of study, and Internet addiction. According to the results obtained from the IAT, questions "How often do you block out disturbing thoughts about your life with soothing thoughts of the Internet?", "How often do you find yourself anticipating when you will go on-line again?", "How often do you find that you stay on-line longer than you intended?", and "How often do you try to cut down the amount of time you spend on-line and fail?" received the maximum scores and question eight "How often does working on the Internet cause a problem in your work?" obtained the minimum score. The results are compared in Tables 2 and 3.

Based on the descriptive results of the drug addiction questionnaire, the items that received higher ranking than the others were as follows: adolescents' hand vibration (46.2\%), excessive criticism by the family (34.3\%), and pretending to be sick (30.1\%). The mean score of the AAS was $1.87 \pm 1.23$ for boys and $1.75 \pm 1.31$ for girls. Moreover, $8.31 \%$ of the students had a higher score of 3 , which indicates being prone to abusing substances. The results are summarized in Table 4 .

Higher rates of addiction potential were reported in rural areas, public schools, and in the field of arts and humanities. The specific independent $t$-test and analysis of variance showed that there was no significant relationship between sociodemographic variables and being prone to abusing substances. The results are summarized in Table 5 .

\section{Discussion}

The results indicate that students were categorized as normal online users (mean score of the IAT was 41.72 \pm 17.41 ). Approximately two-third of the participants were categorized in the ordinary level (lack of Internet addiction), and 25.2\% had moderate dependency and $3.6 \%$ severe dependency. The mean score of the AAS was $1.87 \pm 1.23$ for boys and $1.75 \pm 1.31$ for girls.

In the third millennium, the Internet plays an increasingly important role in adolescents' lives. Internet attraction has caused most of the adolescents to choose computers instead of interaction with peers and parents. In the present research, gender and Internet addiction had no significant relationship, whereas one study showed that mean Internet use was higher among boys than among girls. ${ }^{9}$

The effect of mothers' literacy on Internet addiction behavior was also confirmed in this study. In other words, Internet addiction was higher among the children of mothers with higher education than those with lower education. Similar results were reported in a study in Taiwan where adolescents with a higher literacy level were more exposed to Internet difficulties. ${ }^{22}$ Another study in Iran revealed that the prevalence of problematic Internet use was significantly higher among 
Table 2 Distribution of the IAT (N=385)

\begin{tabular}{|c|c|c|c|c|}
\hline \multirow[t]{2}{*}{ No } & \multirow[t]{2}{*}{ Question } & \multicolumn{3}{|c|}{ Answer options, $\mathbf{n}(\%)$} \\
\hline & & $\begin{array}{l}\text { Never } \\
\text { and rarely }\end{array}$ & $\begin{array}{l}\text { Occasionally } \\
\text { and frequently }\end{array}$ & $\begin{array}{l}\text { Often and } \\
\text { always }\end{array}$ \\
\hline 1 & How often do you find that you stay on-line longer than you intended? & |3| (34.02) & $167(43.37)$ & $87(22.59)$ \\
\hline 2 & How often do you neglect household chores to spend more time on-line? & I7I (44.4I) & $138(35.84)$ & $76(19.74)$ \\
\hline 3 & How often do you prefer the excitement of the Internet to intimacy with your partner? & $187(48.57)$ & $119(30.90)$ & $79(20.51)$ \\
\hline 4 & How often do you form new relationships with fellow on-line users? & $186(48.31)$ & $118(30.64)$ & $81(21.03)$ \\
\hline 5 & $\begin{array}{l}\text { How often do others in your life complain to you about the amount of time you spend } \\
\text { on-line? }\end{array}$ & $177(45.97)$ & $127(32.98)$ & $81(21.03)$ \\
\hline 6 & $\begin{array}{l}\text { How often do your grades or school work suffers because of the amount of time you } \\
\text { spend on-line? }\end{array}$ & $183(47.53)$ & $138(35.84)$ & $64(16.62)$ \\
\hline 7 & How often do you check your email before something else that you need to do? & $226(58.70)$ & $102(26.49)$ & $57(14.80)$ \\
\hline 8 & How often does your job performance or productivity suffer because of the Internet? & $200(51.94)$ & $145(37.66)$ & $40(10.38)$ \\
\hline 9 & $\begin{array}{l}\text { How often do you become defensive or secretive when anyone asks you what you do } \\
\text { on-line? }\end{array}$ & $216(56.10)$ & $108(28.05)$ & $61(15.84)$ \\
\hline 10 & $\begin{array}{l}\text { How often do you block out disturbing thoughts about your life with soothing thoughts of } \\
\text { the Internet? }\end{array}$ & $136(35.32)$ & $151(39.22)$ & $98(25.45)$ \\
\hline II & How often do you find yourself anticipating when you will go on-line again? & $155(40.25)$ & $149(38.70)$ & $8 \mathrm{I}(2 \mathrm{I} .03)$ \\
\hline 12 & How often do you fear that life without the Internet would be boring, empty, and joyless? & $224(58.18)$ & $97(25.19)$ & $64(16.62)$ \\
\hline 13 & $\begin{array}{l}\text { How often do you snap, yell, or act annoyed if someone bothers you while you are } \\
\text { on-line? }\end{array}$ & $213(55.32)$ & $117(30.38)$ & $55(14.28)$ \\
\hline 14 & How often do you lose sleep due to late-night log-ins? & $191(49.61)$ & $105(27.27)$ & $89(23.11)$ \\
\hline 15 & $\begin{array}{l}\text { How often do you feel preoccupied with the Internet when off-line, or fantasize about } \\
\text { being on-line? }\end{array}$ & $170(44.15)$ & $136(35.32)$ & $79(20.51)$ \\
\hline 16 & How often do you find yourself saying "just a few more minutes" when on-line? & $17 \mid(44.41)$ & $127(32.98)$ & $87(22.59)$ \\
\hline 17 & How often do you try to cut down the amount of time you spend on-line and fail? & $152(39.48)$ & $143(37.14)$ & $90(23.37)$ \\
\hline 18 & How often do you try to hide how long you've been on-line? & $216(56.10)$ & $119(30.90)$ & $50(12.98)$ \\
\hline 19 & How often do you choose to spend more time on-line over going out with others? & $219(56.88)$ & $107(27.79)$ & $59(15.32)$ \\
\hline 20 & $\begin{array}{l}\text { How often do you feel depressed, moody or nervous when you are off-line, which goes } \\
\text { away once you are back on-line? }\end{array}$ & $219(56.88)$ & $107(27.79)$ & $59(15.32)$ \\
\hline
\end{tabular}

Abbreviation: IAT, Internet Addiction Test.

university students who had highly educated parents. ${ }^{23}$ In this study, $3.6 \%$ of the adolescents were strongly addicted to the Internet and $25.2 \%$ reported moderate dependence. In consistent with our study, in the study of Khagemogahi and Alasond, ${ }^{11}$ $28 \%$ of participants were moderate Internet users and $2 \%$ had severe Internet addiction. In other studies, Internet addiction was very low, eg, $0.25 \%$ in the study of Tamanaeifar et al. ${ }^{12}$ Other studies revealed higher rates, for example, in the study of Masoudnia, ${ }^{10} 21.7 \%$ of Internet addiction was reported.

Students in the major of applied sciences were reported as highly Internet addicted users. The reason can be attributed to the compulsory existence of computers for education and Internet accessibility. The majority of the students in these fields were from computer and accounting groups. The results of a similar study appealed that Internet addiction was significantly and positively correlated to owning Internet-enabled devices. ${ }^{23}$ Lack of significant relationship between Internet addiction behaviors among urban city students from public and private schools can be related to Internet accessibility.

In this study, drug abuse initiated various problems, including hand vibration (46.2\%), excessive criticism of the family (34.3\%), and pretending to be sick (30.1\%). A similar study found that there was a significant correlation between Internet addiction and distressed behaviors. Students who terribly suffer from mental illness may not be able to deal enthusiastically with their problems and therefore go toward virtual communications. ${ }^{9}$ A further study in Iran indicated that feeling lack of support and not having communications with others may lead to chronic pain. According to the interviews, these feelings increase their tendency toward drug abuse. ${ }^{24}$

In the present study, approximately one-third of the students were taking medicine or sleeping drugs without physicians' prescription, which may be because of medicine availability, lack of control by the family, society, and parents' unawareness. Moreover, $79 \%$ of the students preferred talking with others instead of using medicine for alleviating their concerns. Hence, it can be inferred that if an adolescent does not have someone to talk with, she/he may use tranquilizers and sleeping drugs. The results of a similar research project in China revealed that it is necessary to improve parents' and adolescents' awareness of the risks of non-medical use of any prescription drug. ${ }^{25}$ 
Table 3 Comparing sociodemographic variables and Internet addiction $(\mathrm{N}=385)$

\begin{tabular}{|c|c|c|c|}
\hline \multirow[t]{2}{*}{ Variable } & \multicolumn{2}{|c|}{$\begin{array}{l}\text { Level of Internet } \\
\text { addiction (\%) }\end{array}$} & \multirow[t]{2}{*}{$p$-value ${ }^{a}$} \\
\hline & Moderate & Severe & \\
\hline \multicolumn{4}{|l|}{ Gender } \\
\hline Male & 25.25 & 4.12 & \multirow[t]{2}{*}{0.912} \\
\hline Female & 25.13 & 3.14 & \\
\hline \multicolumn{4}{|l|}{ Family residence } \\
\hline Rural & 24.29 & 3.73 & \multirow[t]{2}{*}{0.25} \\
\hline Urban & 29.68 & 3.12 & \\
\hline \multicolumn{4}{|l|}{ Type of school } \\
\hline Free public school & 25 & 3.71 & \multirow[t]{2}{*}{0.364} \\
\hline Private school & 25.84 & 3.37 & \\
\hline \multicolumn{4}{|l|}{ Fields of education } \\
\hline Math and physics & 18.91 & 2.7 & \multirow{5}{*}{0.777} \\
\hline Experimental sciences & 28 & 4 & \\
\hline Humanities and literature & 27.77 & 1.38 & \\
\hline Vocational & 29.06 & 4.65 & \\
\hline Technical & 21.79 & 5.12 & \\
\hline \multicolumn{4}{|l|}{ Mother's level of education } \\
\hline Primary & 40.34 & 3.85 & \multirow{3}{*}{0.009} \\
\hline High school & 26.08 & 4.34 & \\
\hline Undergraduate & 33.78 & 6.75 & \\
\hline \multicolumn{4}{|l|}{ Father's level of education } \\
\hline Primary & 47.9 & 3.17 & \multirow{3}{*}{0.426} \\
\hline High school & 23.68 & 3.5 & \\
\hline Undergraduate & 28.44 & 6.89 & \\
\hline
\end{tabular}

Note: a Multivariate logistic regression analysis.

The results of our study showed that $8.3 \%$ of the participants were at risk of drug abuse difficulties. Furthermore, $\sim 15 \%$ of students living in rural areas and $9 \%$ of students living in urban areas were categorized as prone to abusing substances. This important issue may be due to recent cultural, economic, and social changes in the rural areas of Iran.

In the study of Bashirian et al, ${ }^{26} 11.1 \%$ of high school students had a smoking history, $4.3 \%$ had drug abuse experience, and $12 \%$ had intention for drug abuse. Moreover, in another study, the prevalence of drug abuse among students of medical sciences was $1.3 \% .{ }^{27}$ Interestingly, a study among medical science students in Iran indicated that $27.6 \%$ of male students consumed alcohol and $82 \%$ used at least one kind of drugs. ${ }^{28}$
Peers have a significant role in developing behavioral patterns among adolescents. The most vulnerable behavioral patterns are adolescents' tendency toward substances that calm down them and are mutual among other peers. Adolescents tend to select friends who share similar activities, relationships, and culture. Thus, concentrating on peers and their interests in order to initiate healthy relationships is essential. ${ }^{29}$

\section{Conclusion}

By taking all abovementioned arguments into consideration, the following conclusions are obtained. First, since one-third of the population were moderate and severe Internet users and considering the rapid progress of technology, it seems necessary to educate students regarding the appropriate amount of using the Internet. Also, since a positive correlation between mother's education level and Internet addiction was observed, training and increasing health literacy level of mothers can be an imperative step in promoting mental and physical health of adolescents. Second, an $8.3 \%$ prevalence of drug abuse and vulnerability of girls in comparison to boys leads us to the significance of paying more attention to adolescents' health and institutionalizing appropriate training programs on drug abuse for girls' schools.

\section{Limitations}

Owing to certain restrictions from the Ministry of Education, a few of the questions related to sexual behaviors, alcohol, and specific drugs were eliminated. In addition, it must be indicated that Urmia is a city with a variety of religions such as Islam, Christian, and Assyria and also different races such as Turk, Kurd, and Aramean. Thus, because of certain protection measures from the Ministry of Education, we were not able to ask students' religions and races and they were not included in the questionnaire.

\section{Acknowledgments}

The study was financed by a grant from the Tabriz University of Medical Sciences (grant number: 5/53/3183-31/08/2014). We really appreciate Deputy of Research and Technology for their

Table 4 Distribution of the questions of AAS $(\mathrm{N}=385)$

\begin{tabular}{|c|c|c|}
\hline \multirow[t]{2}{*}{ Question } & \multicolumn{2}{|l|}{ Answer options } \\
\hline & Correct, n (\%) & False, $\mathbf{n}(\%)$ \\
\hline I have noticed that when I am busy doing something my hand shakes & $178(46.2)$ & $207(53.8)$ \\
\hline I've never run afoul of the law & 300 (77.9) & $85(22.1)$ \\
\hline My parents and family members are complaining too much about me & $132(34.3)$ & $253(65.7)$ \\
\hline I remember to get rid of the cobwebs, I made myself sick & $116(30.1)$ & $269(69.9)$ \\
\hline Never without a prescription, I do not use drugs or sleeping pills & $253(65.7)$ & $132(34.3)$ \\
\hline To reduce the problems and concerns, talking to others is more suitable than using drugs & 307 (79.7) & $78(20.3)$ \\
\hline
\end{tabular}

Note: Analyzed by descriptive statistics.

Abbreviation: AAS, Addiction Acknowledgement Scale. 
Table 5 Prone to abusing substances in terms of sociodemographic variables $(\mathrm{N}=385)$

\begin{tabular}{lll}
\hline Variable & $\begin{array}{l}\text { Prone to abusing } \\
\text { substances }\end{array}$ & p-value \\
\hline Gender & 8.24 & $0.36^{*}$ \\
Male & 8.37 & \\
Female & & \\
Type of school & 9.79 & $0.58^{*}$ \\
$\quad$ Free public school & 3.37 & \\
$\quad$ Private school & & \\
Field of education & 5.4 & $0.64^{\#}$ \\
Math and physics & 9.33 & \\
Experimental sciences & 12.5 & \\
Humanities and literature & 7.69 & \\
Technical & 6.97 & $0.3^{*}$ \\
Vocational & & \\
Family residence & 15.62 & \\
Rural & 6.85 & $0.6 \mathrm{I}^{\#}$ \\
Urban & & \\
Mother's level of education & 7 & $0.3^{\#}$ \\
Primary school & 9.26 & \\
High school & 6.75 & \\
Undergraduate & 9.52 & \\
Father's level of education & 8.93 & \\
Primary school & 6.03 & \\
High school & & \\
Undergraduate & & \\
\hline Notes: & & \\
\hline
\end{tabular}

Notes: $* p$ for independent $t$-test. $" p$ for analysis of variance.

valuable supports. We also are most grateful for the assistance given by Mrs. Ghalichi, the facilitators, and the participants. Last, but not the least, we would like to show our gratitude to Professor Hamid Allahverdipour and Doctor Kousha who provided insight and expertise that greatly assisted the research.

\section{Disclosure}

The authors report no conflicts of interest in this work.

\section{References}

1. Aghamolaei T, Tavafian SS. [Health behaviors of a sample of adolescents in Bandar Abbas, Iran]. Int J High Risk Behav Addict. 2013;2(1):34-38.

2. World Health Organization [webpage on the Internet]. Maternal, newborn, child and adolescent health. Available from: http://www.who.int/ maternal_child_adolescent/epidemiology/adolescence/en/. Accessed December 15, 2015.

3. Aubi E, Shadnoush M, Nazarzadeh M, et al. Translation and assessment of validity and reliability of the health-promoting lifestyle questionnaire: using factor analysis. Pajoohandeh J. 2012;17(3):114-120. Persian.

4. Mohamadian H, Ghannaee M, Kortdzanganeh J, Meihan L. [Reliability and construct validity of the Iranian version of health promoting lifestyle profile among female adolescent population]. Int J Prev Med. 2013;4(1):42-49.

5. Chen MY, Wang EK, Yang RJ, Liou YM. Adolescent health promotion scale: development and psychometric testing. Public Health Nurs. 2003;20(2):104-110.

6. Chen M-Y, James K, Wang EK. Comparison of health-promoting behavior between Taiwanese and American adolescents: a cross-sectional questionnaire survey. Int J Nurs Stud. 2007;44(1):59-69.

7. Zareipour MA, Eftekhar AH, Azam K, Movahed E. [Study of mental health and its relationship with family welfare in pre-university students in Salmas city in 2010]. J Nurs Res. 2012;9(1):84-93. Persian.
8. Hasanzadeh R, Mohammad S, Rezaei Kiasari A. [Relationship between the use of extreme from technology and educational and psychological state high school students]. QJ Educ Psychol. 2010;1(3):69-81. Persian.

9. Lawrence L, Zi-Wen P, Jin-Cheng M, Jin J. Factors associated with internet addiction among adolescents. Cyberpsychol Behav. 2009;12(5): $551-555$.

10. Masoudnia E. [Problematic cyberspace use and risk of depression disorder incidence among adolescents in Yazd]. Iran J Epidemiol. 2013; 8(4):15-25. Persian.

11. Khagemogahi N, Alasond M. [Study of personality variables predictors of internet addiction]. Ahvaz Med J. 2010;9(4):360-366. Persian.

12. Tamanaeifar M, Arfeei FS, Gandomi Z. [Relationship between internet addiction with neuroticism among high school students, Kashan, Iran]. J Hormozgan Univ Med Sci. 2014;17(1):69-75. Persian.

13. Brook JS, Morojele NK, Pahl K, Brook DW. Predictors of drug use among South African adolescents. J Adolesc Health. 2006;38(1): 26-34.

14. Hawkins D, Catalano R, Miller J. Risk and protective factors for alcohol and other drug problems in adolescence and early adulthood: implications for substance abuse prevention. Psychol Bull. 1992;112(1):64-105.

15. Pourshahbaz A, Shamloo S, Jazayeri A, Ghazi TM. [Structural relations of psychological risk and protective factors of drug abuse in adolescents]. Soc Welfare. 2006;5:31-54. Persian.

16. Golmakani N, Naghibi F, Moharari F, Esmaily H. [Health promoting life style and related factors among female adolescents]. J Midwifery Reprod Health. 2013;1(1):42-49.

17. Young KS. Internet addiction: the emergence of a new clinical disorder. Cyberpsychol Behav. 2009;1(3):237-244

18. Weed N, Butcher S, McKenna T, Ben-Povath Y. New measures for assessing alcohol and drug abuse problems with the MMPI-2: The APS and AAS. J Pers Assess. 1992;58:389-404.

19. Nikmanesh Z, Adrom M, Bakhshani NM. Minnesota multiphasic personality inventory score as a predictor of addiction potential in youth. Int J High Risk Behav Addict. 2012;1(1):20-24.

20. Rostami R, Nosratabadi M, Mohammadi F. [Primary evaluation of the diagnostic accuracy of the AAS, MAC-R, and APS]. Pschological Res. 2007;10(12):11-28. Persian.

21. Bahri N, SadeghMoghadam L, Khodadost L, Mohammadzade J, Banafsheh E. [Internet addiction status and its relation with students' general health at Gonabad University of Medical Sciences]. Modern Care J. 2011;8(3):166-173. Persian.

22. Ko CH, Yen JY, Chen CC, Chen SH, Yen CF. Gender differences and related factors affecting online gaming addiction among Taiwanese adolescents. J Nerv Ment Dis. 2005;193(4):273-277.

23. Ghahremani L, Nazari M. [Internet addiction and its effect on the academic achievement students of Shiraz University of medical sciences: addiction-driven behaviors]. Media. 2013;4(1):44-51. Persian.

24. Safari Hajat Aghaii S, Kamaly A, Esfahani M. Meta-analysis of individual and environmental factors that influence people's addiction tendencies. Int J High Risk Behav Addict. 2012;1(3):92-99.

25. Guo L, Xu Y, Deng J, et al. Non-medical use of prescription pain relievers among high school students in China: a multilevel analysis. $B M J$ Open. 2015;5(7):e007569.

26. Bashirian S, Haidarnia A, Allahverdipour H, Hajizadeh E. [Application of theory of planned behavior in predicting factors of substance abuse among adolescents]. J Fasa Univ Med Sci. 2012;2(3):156-162. Persian.

27. Khazaei H, Najafi F, Far AA. Substance abuse prevalence and related factors among students of Kermanshah University of Medical Science in 2011. J Kermanshah Univ Med Sci. 2013;17(3):197-205. Persian.

28. Babaei Heydarabadi A, Ramezankhani A, Barekati H, et al. Prevalence of substance abuse among dormitory students of Shahid Beheshti University of Medical Sciences, Tehran, Iran. Int J High Risk Behav Addict. 2015;4(2):e22350.

29. Patrick ME, Schulenberg JE, Maggs J, Maslowsky J. Substance use and peers during adolescence and the transition to adulthood: selection, socialization, and development. In: Sher KJ, editor. The Oxford Handbook of Substance Use and Substance Use Disorders. Oxford: Oxford University Press; 2016:art4. 
Psychology Research and Behavior Management is an international, peerreviewed, open access journal focusing on the science of psychology and its application in behavior management to develop improved outcomes in the clinical, educational, sports and business arenas. Specific topics covered in the journal include: Neuroscience, memory and decision making; Behavior
Submit your manuscript here: https://www.dovepress.com/psychology-research-and-behavior-management-journal 